Fisheries Research

November 2016, Volume 183 Pages 396-400

http://dx.doi.org/10.1016/i.fishres.2016.07.011

http://archimer.ifremer.fr/doc/00346/45695/

(c) 2016 Published by Elsevier B.V.

\title{
Survival of discarded Nephrops norvegicus after trawling in the Bay of Biscay
}

\author{
Méhault Sonia ${ }^{1 ? *}$, Morandeau Fabien ${ }^{1}$, Kopp Dorothée ${ }^{1}$ \\ ${ }^{1}$ Ifremer, Unité de Sciences et Technologies halieutiques, Laboratoire de Technologie et Biologie \\ Halieutique, 8 rue François Toullec, F-56325 Lorient Cedex, France \\ *Corresponding author : Sonia Méhault, email address : sonia.mehault@ifremer.fr
}

\begin{abstract}
:
The new Common Fisheries Policy may exempt some species from the landing obligation if a high survival rate can be demonstrated among discards. This study focuses on the survival capacity of Nephrops norvegicus discarded from trawlers of the Bay of Biscay (France). Three sea trials were conducted on board 3 commercial trawlers and 15 fishing operations were sampled. The vitality of Nephrops was classed into three categories (healthy, moribund or dead) before release at sea and samples of healthy and moribund individuals were kept in captivity on Nephrops grounds for three days. A Generalised Linear Model was used to examine the variability in the proportion of healthy Nephrops discarded, which was significantly influenced by tow duration, duration of air exposure and temperature, as well as individual length. By combining the results on vitality before release at sea with those on survival in captivity following re-immersion, resampled by bootstrapping, it was calculated that $51 \%$ [42$60 \%$ ] of discarded Nephrops would survive after three days of re-immersion. We discuss the sources of variability in survival rate, as well as the implications of a potential exemption from the landing obligation for this species.
\end{abstract}

Keywords : Vitality, Captivity, South western waters, Bottom trawl, GLM

\section{Introduction}

The European Union recently modified its Common Fisheries Policy and brought into force the prohibition of discarding catches (European Commission, 2013). Nonetheless, article 15 paragraph 2(b) of the regulation mentions the possibility of exemption from the landing obligation for species for which "scientific evidence demonstrates high survival rates". Research has thus shown that not all the discarded individuals die and, depending on biological, environmental and technical parameters, their survival rate could be quite high (Revill, 2012). The biological factors potentially influencing animal survival include: species (Broadhurst et al., 2006), size (Davis and Olla, 2002 and Benoit et al., 2013) physical injuries 
(Depestele et al., 2014) and physiological stress (Bergmann et al., 2001). Environmental factors such as temperature, depth and light conditions have also been found to influence an animal"s ability to recover after having been thrown back into the water (Davis and Olla, 2002 and Giomi et al., 2008). Finally, technical parameters such as catch size (Tenningen et al., 2012), handling practices on deck (Castro et al., 2003 and Macbeth et al., 2006), duration of air exposure (Davis, 2002, Broadhurst et al., 2006, Benoit et al., 2010, Benoit et al., 2012 and Benoit et al., 2013) and gear type (Neilson et al., 1989) are amongst those with the strongest effects on organism survival.

In this regard, it is necessary to develop approaches for survival experiments that will provide information about species potential for "high survival rate". Three methods were identified by the Expert Working Group 13-16 (EWG13-16) from the Scientific, Technical and Economic Committee for Fisheries (STECF, 2013), namely, captive observation (Revill et al., 2013 and Depestele et al., 2014), vitality and reflex assessments (Davis and Ottmar, 2006, Humborstad et al., 2009 and Davis, 2010) and tagging or biotelemetry experiments (Donaldson et al., 2008 and Yergey et al., 2012). These measures of animal survival are especially important as they could be used for stock assessments. Following the implementation of the landing obligation, any individuals that would otherwise have survived the discarding process would thereafter contribute to the overall fishing mortality of the stock. This has significant implications for stocks that include discards in their assessment: determination of discard survival will now influence the assessment process and the setting of total allowable catch (TAC). This is particularly true for stocks simply assumed to have no chance of survival after discarding (either because it is considered negligible or because accurate estimates are not available) or for the few species that already formally have a discard survival factor incorporated in the stock assessment process, such as Nephrops.

For the Nephrops fishery in Bay of Biscay, the survival rate of discards from trawlers was studied by Gueguen and Charueau (1975) and by Morizur et al. (1982). These authors concluded that $30 \%$ of discarded Nephrops could survive, and this rate was later adopted by the International Council for the Exploration of the Sea (ICES) who have since used this figure in the stock assessment procedure. However, the gears used to fish this species have evolved since the 1970s: the codend mesh size has gradually increased from $55 \mathrm{~mm}$ in $1975-70$ or $80 \mathrm{~mm}$ today and, while Nephrops trawlers were previously rigged with a single gear, they are now rigged with twin gears, leading to a reduction of the catch volume per codend. The French national fishing committee has also taken restrictive measures in order to reduce the discard rate and preserve the stock: the minimum landing size was set at $9 \mathrm{~cm}(28 \mathrm{~mm}$ cephalothoracic length) and, in 2007, the fishermen had to adopt at least one selective device from the following: a codend mesh size of $80 \mathrm{~mm}$, a flexible grid, or a bottom square mesh panel (CNPMEM, 2010). In 2011, one more selective device, a square mesh cylinder, was added to the legislation. However, despite these technical measures, the discard rates in this mixed bottom trawl fishery remain high, with an average of $49 \%$ of the catch discarded in 2013 (Cornou et al., 2015).

The present paper reports a new evaluation of the survival rate of discarded Nephrops in the Bay of Biscay using two methods recommended by EWG13-16 ( STECF, 2013): vitality assessment and captive observation of captured individuals. 
We also aimed to determine if this survival rate was influenced by a biological factor (size), an environmental parameter (air temperature) and aspects related to the operational practices (tow duration and duration of air exposure).

\section{Materials and methods}

\subsection{Sampling strategy}

The survival experiment was conducted on the Nephrops grounds of the Bay of Biscay known as the "Grande Vasière" ( Dubrulle et al., 2007), extending from $46^{\circ} 00 \mathrm{~N}$ to $47^{\circ} 50 \mathrm{~N}$ and $4^{\circ} 50 \mathrm{~W}-3^{\circ} 00 \mathrm{~W}$, on the continental shelf off the Atlantic coast of France at depths between 65 and $113 \mathrm{~m}$ (Fig. 1). Three commercial trawlers were used for sampling during the fishing season in July and October 2009 and in July 2010 (Table 1). All vessels were rigged with twin bottom trawls, which are commonly used to target Nephrops in this fishery ( Macher et al., 2008). The hauls sampled were conducted under normal commercial conditions: the mean duration of the tows was $2.3 \mathrm{~h}(1.27-3.25)$, the towing speed ranged between 3 and 4 knots, the codend mesh size was $80 \mathrm{~mm}$ (CNPMEM, 2010) and the net extension was equipped with the compulsory square mesh panel (European Union, 1998). The crew was asked to keep onboard handling practices as usual in order to obtain samples representative of normal commercial fishing conditions.

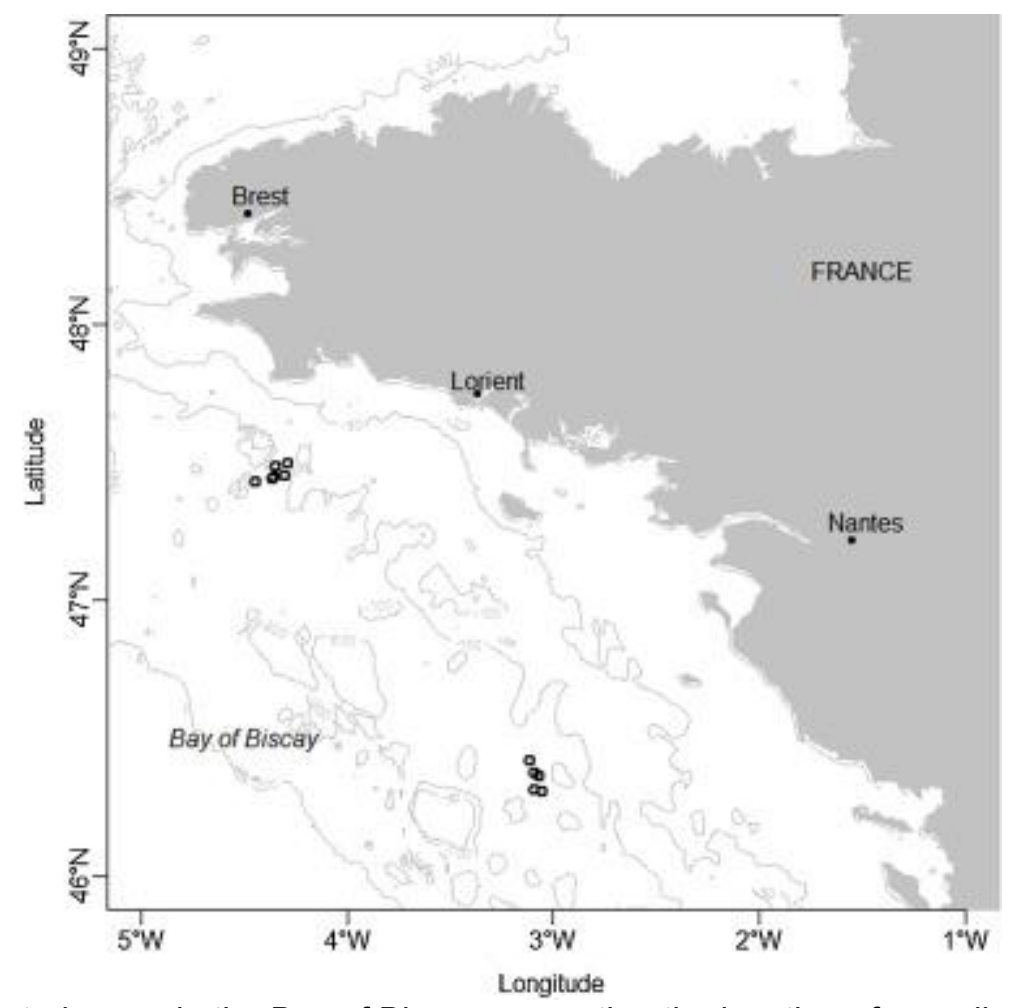

Fig. 1. Map of the study area in the Bay of Biscay presenting the location of sampling sites (black dots) and the $50 \mathrm{~m}, 100 \mathrm{~m}$ and $200 \mathrm{~m}$ iso-depth lines (grey lines). 
Table 1. Summary of data from vitality and survival experiments.

\begin{tabular}{lcccccc}
\hline $\begin{array}{c}\text { Sampling } \\
\text { period }\end{array}$ & $\begin{array}{c}\text { Fishing } \\
\text { Operation } \\
\text { number }\end{array}$ & $\begin{array}{c}\text { Time of } \\
\text { exposure to } \\
\text { air (decimal } \\
\text { hours) }\end{array}$ & $\begin{array}{c}\text { Air temperature } \\
\left({ }^{\circ} \text { C) }\right.\end{array}$ & $\begin{array}{c}\text { Tow } \\
\text { duration } \\
\text { (decimal } \\
\text { hours) }\end{array}$ & $\begin{array}{c}\text { Number of } \\
\text { Nephrops } \\
\text { sampled for } \\
\text { vitality }\end{array}$ & $\begin{array}{c}\text { Number of } \\
\text { Nephrops } \\
\text { sampled for } \\
\text { survival }\end{array}$ \\
\hline & 1 & NA & NA & NA & 0 & 94 \\
July 2009 & 2 & 0.93 & 18 & 2.93 & 237 & 69 \\
& 3 & 1.45 & 17 & 3.03 & 269 & 99 \\
& 4 & 1.00 & 21 & 1.67 & 277 & 100 \\
& 5 & 0.72 & 23 & 1.27 & 329 & 75 \\
& 6 & 1.65 & 17 & 2.33 & 119 & 96 \\
October & 7 & 0.82 & 20 & 2.10 & 190 & 100 \\
$\mathbf{2 0 0 9}$ & 8 & 1.42 & 18 & 1.55 & 72 & 100 \\
& 9 & 1.12 & 15 & 2.02 & 81 & 100 \\
& 10 & 1.33 & 16 & 1.93 & 79 & 99 \\
& 11 & 1.08 & 22 & 3.25 & 256 & 140 \\
July 2010 & 12 & 0.83 & 20 & 3.25 & 286 & 93 \\
& 13 & 0.67 & 20 & 2.75 & 334 & 98 \\
& 14 & NA & NA & NA & 0 & 146 \\
& 15 & 1.08 & 20 & 1.75 & 404 & 148 \\
\hline
\end{tabular}

\subsection{Survival rate}

Survival rate estimation was made using two independent procedures: vitality assessments and field captive observations. Vitality assessments estimated survival as the proportion of individuals alive prior to discarding in a given sample. From field captive observations, survival rate was estimated as the proportion of individuals that survived a re-immersion phase, based on a sample of living individuals at the time of re-immersion. Both estimates were used to compute the overall survival rate of discarded Nephrops.

\subsubsection{Vitality assessment}

Thirteen fishing operations were carried out to assess the vitality state $(\mathrm{V})$ of Nephrops before discard. Samples of Nephrops were taken randomly from the discard heap. Sample size ranged from 72 to 404 individuals (mean $=225$ ), with 2933 Nephrops examined in total ( Table 1). Cephalothoracic length was measured and vitality state was assessed visually (Gueguen and Charueau, 1975 and Castro et al., 2003). Vitality state was rated at three levels: (1) healthy $(\mathrm{H})$ : the Nephrops was able to do a "tail-flip" and its body is lively, (2) moribund (M): the Nephrops was alive (e.g. it moves its legs or antenna) but has no strength in its body (3) dead (D): the Nephrops did not move at all and has no strength. Although more detailed vitality state scales were available (e.g. Ridgway et al., 2006), this was considered the best compromise between sample size and sample treatment time. Proportions of healthy, moribund and dead individuals were calculated for each fishing operation. 


\subsubsection{Field captive observations}

\subsubsection{Experimental setup}

Living Nephrops that were either healthy or moribund, were put into numbered plastic tubes (1 Nephrops per tube), which were themselves put in oyster farming bags to be re-immerged close to the site where they were caught. The tubes were made of perforated PVC with dimensions of $25 \mathrm{~cm}$ length and $5 \mathrm{~cm}$ diameter. They were closed by pieces of net at each extremity (Fig. 2). Each bag contained 25 Nephrops tubes, which were immerged for 3 days, in accordance with the methodology proposed by Gueguen and Charueau (1975) in the bay of Biscay.
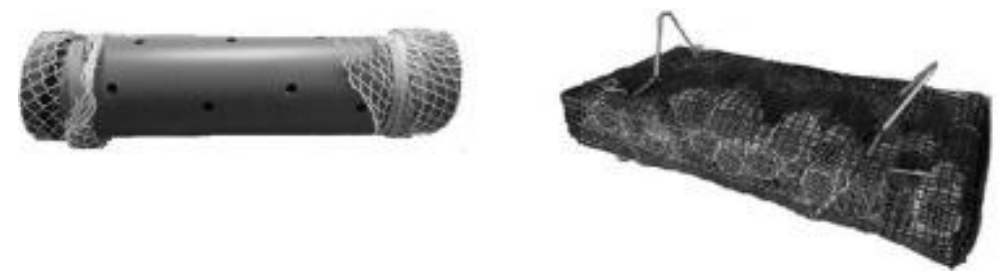

Fig. 2. Tubes (left side) and bags (right side) used for field captive observations. Tubes characteristics: Dimensions $=25 \mathrm{~cm}$ length $\times 5 \mathrm{~cm}$ diameter, number of holes $=15$, holes diameter $=7 \mathrm{~mm}$, stretch mesh size $=12 \mathrm{~mm}$. Bags characteristics: Dimensions $=70 \times 40 \times 15 \mathrm{~cm}$, square mesh size $=15 \times 15 \mathrm{~mm}$, number of tubes per bag $=25$.

\subsubsection{Control group}

Control experiments were conducted to test the effect of captivity on Nephrops survival. Creels were used to catch control Nephrops with minimum stress. They were baited and immerged for two days close to the trawl fishing grounds. The catch was composed of 17 individuals of $N$. norvegicus and 138 specimens of plated lobster (Munida rugosa) all of which were healthy. The control Nephrops sample was small. Considering that $M$. rugosa and Nephrops are both decapods, with similar order of magnitude of body length, living in the same habitat and presenting the capacity to resist to air exposure ( Bergmann and Moore, 2001), M. rugosa was considered a suitable replacement for Nephrops in the control group. Individuals were put in experimental tubes and bags and re-immerged for three days. Control group mortality is provided as an indicator of uncertainty in test group survival rate, but is not included in the calculation.

\subsubsection{Test group}

Fifteen fishing operations were sampled and 1557 healthy and moribund Nephrops were re-immerged in plastic tubes and bags for three days (Table 1). For each of the fifteen hauls, a sample of about 100 living Nephrops to be discarded was taken randomly from the heap. The vitality of each sampled individual was assessed. The individuals were then put in tubes and bags for re-immersion. To keep time of air exposure representative of commercial fishing conditions, the Nephrops bags were put back on the sea floor after the crew finished processing the catch and had cleaned the deck of discards. Following the re-immersion period and directly after hauling the bags back on board, the vitality state of each individual was reassessed. For each haul, out of the individuals that had been healthy before re-immersion, the proportions that were now moribund, dead or that were still healthy after three days in 
the sea were calculated, as were the proportions of moribund individuals that were later found to be healthy, dead or that remained moribund. The proportion of individuals still alive after re-immersion was recorded for each sample.

\subsubsection{Survival rate: combination of vitality and field captive observations}

Since dead animals were not re-immerged, the observations on captive Nephrops only provide the survival rate of either healthy or moribund individuals without accounting for mortality in the initially discarded population. To get the survival rate of a batch of discarded Nephrops, survival rates from captive observations have to be combined to the proportions of healthy, moribund or dead animals before discard, assessed in the vitality experiment.

The calculation of the survival rate was based on the assumption that the chance of an individual surviving after re-immersion only depends on its prior vitality state. The percentage of healthy individuals that remained healthy and the percentage of moribund individuals that became healthy from the field captive experiment were calculated for each haul. These indices were then multiplied by the proportion of healthy and moribund individuals in each sample of the vitality experiment (Eq. (1)). In order to avoid overestimation of survival rate, only individuals found to be healthy after re-immersion were considered alive, and individuals remaining moribund after re-immersion were considered as dead. Overall survival rate per haul was expressed as:

Equation (1)

$\mathrm{SR}=\left(M_{b} \rightarrow H_{a}\right) / M_{b}{ }^{*} M_{b} /\left(M_{b}+H_{b}+D_{b}\right)+\left(H_{b} \rightarrow H_{a}\right)^{*} H_{b} /\left(M_{b}+H_{b}+D_{b}\right)$

With

$\mathrm{SR}=$ discarded Nephrops survival rate per haul

$M=$ number of moribund individuals

$\mathrm{H}=$ number of healthy individuals

$D=$ number of dead individuals

$b=$ before re-immersion

$a=$ after three days of re-immersion

$\rightarrow=$ became

\subsection{Statistical analysis}

For each haul, a series of explanatory variables were collected that included a biological parameter (cephalothoracic length of Nephrops), an environmental parameter (ambient air temperature) and fishing operation parameters (tow duration and duration of air exposure). 
A Generalised Linear Model (GLM) was used to describe the variability of the vitality before discard according to the explanatory variables. Binomially distributed errors and logit link were used to fit the GLM to the proportion of healthy individuals observed from the vitality assessment. The selection of the model was based on the AIC value (Akaike, 1974), and the distribution and homogeneity of the residuals were checked to validate the model.

The survival rate was computed from Eq. (1) for the 13 hauls for which both the vitality estimates before discard and survival of Nephrops discarded alive had been recorded (Table 1). Mean survival rate was computed from bootstrap resampling with replacement and 1000 iterations, and 95\% confidence intervals were calculated after verifying that the data met the distributional assumptions.

All analyses were conducted with R 3.0.2 software ( $R$ Development Core Team).

\section{Results}

The cephalothoracic length of the sampled Nephrops ranged from 10 to $50 \mathrm{~mm}$ (from 5 to $15 \mathrm{~cm}$ total length), with mean length of $26.7 \mathrm{~mm}( \pm 7.5 \mathrm{SD}$.). From the vitality assessments, $40 \%$ ( $\pm 21 \mathrm{SD}$.) of the Nephrops were found healthy before being discarded, $32 \%$ ( \pm 12 SD.) were moribund and $28 \%$ ( \pm 15 SD.) were dead. The GLM fitted to the observed percentages of healthy individuals among the discards, showed that all explanatory variables included in the model, had a significant effect on this proportion (all $p$-values $<0.05$ ). Thus air temperature, tow duration, duration of air exposure and the cephalothoracic length all had negative effects on the vitality of discarded Nephrops ( Table 2).

Table 2. Summary of variables, estimates, standard errors, $\mathbf{Z}$ and $p$-values of the model used to analyse the proportion of healthy $N$. norvegicus to be discarded.

\begin{tabular}{lllll}
\hline & & \multicolumn{3}{c}{ After three days re-immersion } \\
\cline { 3 - 5 } Before & Mead & Moribund & Healthy \\
re-immersion & Healthy & $35.6(11.8)$ & $2.7(3.4)$ & $61.7(13.4)$ \\
& $20.8(10.8)$ & $2.9(2.8)$ & $76.2(12.6)$ \\
\hline
\end{tabular}

Field captive observations of the creel-caught control group showed that the current captivity conditions only incurred a very low mortality as only 1 Nephrops (6\%) and 6 Munida (4\%) were observed dead after three days of re-immersion. In the test group, observations of the vitality state of Nephrops before and after re-immersion showed that healthy individuals tended to remain healthy and moribund individuals had a high capacity for recovery. Although a higher rate of mortality was observed among moribund individuals than healthy ones, very few $N$. norvegicus assessed either healthy or moribund before re-immersion were assessed as moribund after reimmersion (Table 3). 
Table 3. Summary of variables, estimates, standard errors, $Z$ and $p$-values of the model used to analyse the proportion of healthy $N$. norvegicus to be discarded.

\begin{tabular}{lllll}
\hline \hline Variable & Estimate & SE & $\boldsymbol{Z}$ & $\boldsymbol{p}$ \\
\hline Time to air exposure & -0.46 & 0.20 & -2.25 & 0.03 \\
Cephalothoracic length & -0.06 & 0.01 & -4.54 & $<0.0001$ \\
Tow duration & -0.46 & 0.06 & -7.17 & $<0.0001$ \\
Air temperature & -0.26 & 0.03 & -8.90 & $<0.0001$ \\
\hline
\end{tabular}

The survival rates obtained by combining the proportions of living individuals before re-immersion and the proportions able to survive the re-immersion period in captivity (Eq. (1)) for 13 hauls ranged from 18 to $72 \%$, and were normally distributed. The bootstrap re-sampling indicated that the mean survival rate of discarded Nephrops in the current study was $51 \%[42-60 \%]$.

\section{Discussion}

Fisheries discards are estimated to be about 7 million tons per year worldwide (Kelleher, 2005) and the North East Atlantic fisheries are identified in second position of worldwide discards in commercial fisheries (Alverson et al., 1994). Although several tools have proved to significantly reduce discards (Revill et al., 2006, Valentinsson and Ulmestrand, 2008 and Frandsen et al., 2009), the discard rate in the Nephrops trawl fishery remains high (Cornou et al., 2013 and Cornou et al., 2015) and the landing obligation to be brought into force by the reform of the European Common Fisheries Policy (CFP) implies that discarding Nephrops, a species under quota in the Bay of Biscay, will soon be prohibited. However, because there is the mention of potential exemptions for species for which "scientific evidence demonstrates high survival rates", N. norvegicus could be one of these exemptions as it shows a survival potential of $51 \%$ after discard in the Bay of Biscay. This survival rate is either higher or in the same range as those observed by most other authors in European seas. In the same fishery, Gueguen and Charueau (1975) found that $17 \%$ of discarded animals were healthy and $41 \%$ moribund after $1 \mathrm{~h}$ of air exposure and three days of re-immersion. From these observations, the average of $30 \%$ survival was agreed by ICES for stock assessment. Wileman et al. (1999) found a survival rate of $31 \%$ in the North West of Scotland, Castro et al. (2003) found 23$60 \%$ in the South of Portugal and Harris and Andrews (2005) found $31 \%$ on the West coast of Scotland. The protocols differed between these different studies, which could have led to differences in the final estimates of survival. Guegen and Charuau (1975) re-immerged discarded Nephrops in cages in which the density ranged from 30 to 140 individuals per batch. Morizur et al. (1982), who used the same method in the Bay of Biscay, pointed out that a high density in the cages may have increased the mortality rate induced by the experiment (Nephrops are more vulnerable to amphipods if stored at high density, and individuals may become aggressive and damage each other). 
To address this issue, Wileman et al. (1999) and Castro et al. (2003) re-immerged all the Nephrops in their studies in holding pens with individual compartments, sampled randomly regardless of their vitality state (i.e. including animals that did not show any signs of life). In the same way, our method was based on individual re-immersion, but only used animals that appeared to be alive, which had been randomly sampled among moribund or healthy individuals. The combination of an assessment of surviving individuals after re-immersion and vitality before discard is an alternative way to estimate survival rate of a fishing operation, permitting larger sample sizes for both vitality and survival observations.

The GLM fitted to the proportion of healthy individuals before discard indicates that the larger the individuals, the lower their probability of being healthy. The samples observed contained individuals larger than the commercial size, discarded mainly because of their moulting status, which makes them less commercially valuable. Morizur et al. (1982) indicated that this biological state may influence their capacity to withstand the fishing operation and catch handling. Length of air exposure, temperature and tow duration also had a significant effect on the survival of discarded Nephrops. Higher survival rates have generally been observed with lower air temperature (Giomi et al., 2008) but our experiment focused on the period of highest fishing activity for this seasonal métier, i.e. summertime.

The ranges of parameters observed during our experiment are representative of the practices of the French Nephrops fleet in the Bay of Biscay (e.g. catch handling or sorting practices). However, conditions such as the time of captivity or protection from predation in the water column may have affected the results. Several authors found that mortality may occur after 3 days of captivity (Castro et al., 2003 and Wileman et al., 1999). In the current study, 3\% of Nephrops remained moribund at the end of this period of time, indicating that these individuals may have needed more than 3 days to either recover or die. In order to not over estimate survival, individuals found moribund at the end of the observation period were considered as dead. The mortality in the control group being low (4-6\%), the uncertainty in the survival estimate due to captive conditions was meant to be low as well.

Even though our experiments were carried out on three different vessels to cover a wide range of crew experience, as the level of physical injuries suffered by discarded individuals may vary from one vessel to another. Depending on crew sorting practices and the layout of the deck, Nephrops may be more or less trampled and damaged during the sorting process. To optimize their chances of survival, the use of a sorting table and evacuation gutter on board would be a suitable option to minimize the duration of air exposure and physical damage. Such infrastructure would be beneficial for the stock since Chapman et al. (2000) demonstrated that Nephrops that survive after being thrown back to the sea continue to grow and reproduce.

In the Bay of Biscay, discarded Nephrops accounted for between 852 and 2044 tons in 2013 ( Cornou et al., 2015). Efforts continue to improve gear selectivity and these are worthwhile since survival of escapees is usually higher than that of discards (Wileman et al., 1999; Guegen and Charuau, 1975). Efforts to improve gear selectivity to reduce discards are worthwhile since survival of escapees is usually higher than that of discards (Wileman et al., 1999; Guegen and Charuau, 1975). 
Improving catch handling on board would give the best chance of survival of discards and contribute to the re-integration of a considerable number of animals into the population, whereas the landing obligation proposed under the new Common Fishery Policy would increase the fishing mortality and generate an equivalent loss for the stock biomass.

\section{Acknowledgements}

The authors thank the crews of the Marie-Lou and I"Atlantique for their help on board to conduct the survival experiment and Aglia for the logistic organisation of the experiment and its observer J.P. Cuillandre for the collection of the data on board. They also thank the Ifremer team who greatly contributed to the preparation of the experimental material, particularly B. Dubé, C. Vogel and M. Robert. This study was a special collaborative project between fishermen and scientists, funded under the European Interreg Atlantic Arc PRESPO project (FEDER).

\section{References}

Akaike, H., 1974. A new look at the statistical model identification. IEEE Trans. Auto.Control. 19, 716-722.

Alverson, D.L., Freeberg, M.H., Murawski, S.A., Pope, J.G., 1994. A global assessment of fisheries bycatch and discards. FAO Fisheries technical paper,no. 339. FAO, Rome.

Benoit, H.P., Hurlbut, T., Chasse, J., 2010. Assessing the factors influencing discard mortality of demersal fishes using a semi-quantitative indicator of survival potential. Fisheries Res. 106, 436-447.

Benoit, H.P., Hurlbut, T., Chasse, J., Jonsenb, I.D., 2012. Estimating fishery-scale rates of discard mortality using conditional reasoning. Fisheries Res. 125- 126, 318-330.

Benoit, H.P., Plante, S., Kroiz, M., Hurlbut, T., 2013. A comparative analysis of marine fish species susceptibilities to discard mortality: effects of environmental factors, individual traits, and phylogeny. ICES Journal of Marine Science. 70(1), 99113.

Bergmann, M. and Moore, P. G. 2001. Survival of decapod crustaceans discarded in the Nephrops fishery of the Clyde Sea area, Scotland. ICES Journal of Marine Science. 58, 163-171.

Bergmann, M., Taylor, A.C. and Moore P.G., 2001. Physiological stress in decapod crustaceans (Munida rugosa and Liocarcinus depurator) discarded in the Clyde 
Nephrops fishery. Journal of Experimental Marine Biology and Ecology. 259, 215229.

Broadhurst, M.K., Suuronen, P., Hulme, A., 2006. Estimating collateral mortality from towed fishing gear. Fish and Fisheries. 7, 180-218.

Castro, M., Araujo, A., Monteiro, P., Madeira, A.M., Silvert, W., 2003. The efficacy of releasing caught Nephrops as a management measure. Fisheries Res. 65, 475484.

Chapman, C.J., Shelton, P.M.J., Shanks, A.M., Gaten, E., 2000. Survival and growth of the Norway lobster Nephrops norvegicus in relation to light-induced eye damage. Marine Biology. 136, 233-241.

Comité National des Pêches Maritimes et des Elevages Marins (CNPMEM), 2010. Conditions d"exercice de la pêche à la langoustine (Nephrops norvegicus) dans les eaux du golfe de Gascogne (divisions CIEM VIII a, b, d et e). Délibération $\mathrm{N}^{\circ}$ 07/2010.

Cornou, A.S., Dimeet, J., Tetard, A., Gaudou, O., Dube, B., Fauconnet, L., Rochet M.-J., 2013. Observations à bord des navires de pêche professionnelle. Bilan de l'échantillonnage 2012. http://dx.doi.org/10.13155/27787.

Cornou, A.-S., Dimeet, J., Tetard, A., Gaudou, O., Quinio-Scavinner, M., Fauconnet, L., Dube, B., Rochet M.-J., 2015. Observations à bord des navires de pêche professionnelle. Bilan de l'échantillonnage 2013. Retrieved from http://dx.doi.org/10.13155/35856, 01/09/2015.

Davis, M.W., 2002. Key principles for understanding fish bycatch discard mortality. Can. J. Fish. Aquat. Sci. 59, 1834-1843.

Davis, M.W., Olla, B.L., 2002. Mortality of lingcod towed in a net as related to fish length, seawater temperature, and air exposure: A laboratory bycatch Study. North American Journal of Fisheries Management. 22(4), 1095-1104.

Davis, M.W., Ottmar, M.L., 2006. Wounding and reflex impairment may be predictors for mortality in discarded or escaped fish. Fisheries Res. 82, 1-6.

Davis, M.W., 2010. Fish stress and mortality can be predicted using reflex Impairment. Fish and Fisheries. 11, 1-11.

Depestele, J., Desender, M., Benoît, H.P., Polet, H., Vincx, M., 2014. Short-term survival of discarded target fish and non-target invertebrate species in the "eurocutter" beam trawl fishery of the southern North Sea. Fisheries Res. 154, 8292.

Donaldson, M.R., Arlinghaus, R., Hanson, K.C., Cooke, S.J., 2008. Enhancing catch-and-release science with biotelemetry. Fish and Fisheries. 9, 79-105. 
Dubrulle, C., Jouanneau, J.M., Lesueur, P., Bourillet, J.F., Weber O., 2007. Nature and rates of fine-sedimentation on a mid-shelf: La Grande Vasière (Bay of Biscay, France). Continental Shelf Research. 27(16), 2099-2115.

European Commission, 2013. Regulation (EU) No 1380/2013 of the European Parliament and of the Council of 11 December 2013 on the Common Fisheries Policy. Official Journal of the European Union. http://eurlex.europa.eu/LexUriServ/LexUriServ.do?uri=OJ:L:2013:354:0022:0061:en:PDF

European Union, 1998. Council Regulation (EC) No 850/98 of 30 March 1998 for the conservation of fishery resources through technical measures for the protection of juveniles of marine organisms

http://eur-

lex.europa.eu/LexUriServ/LexUriServ.do?uri=CONSLEG:1998R0850:20060117:EN: PDF.

Frandsen, R.P., Holst, R., Madsen, N., 2009. Evaluation of three levels of selective devices relevant to management of the Danish Kattegat-Skagerrak Nephrops fishery. Fisheries Res. 97, 243-252.

Giomi, F., Raicevich, S., Giovanardi, O., Pranovi, F., Di Muro, P., Beltramini, M., 2008. Catch me in winter! Seasonal variation in air temperature severely enhances physiological stress and mortality

of species subjected to sorting operations and discarded during annual fishing activities. Hydrobiologia. 606, 195-202.

Gueguen, J., Charueau, A., 1975. Essai de détermination du taux de survie des langoustines hors taille rejetées lors des opérations de pêche commerciale. ICES CM 1975 / K :12.

Harris, R.R., Andrews, M.B., 2005. Physiological changes in the Norway lobster Nephrops norvegicus (L.) escaping and discarded from commercial trawls on the West Coast of Scotland. J. Experimental Marine Biology and Ecology. 320, 195210.

Humborstad, O-B., Davis, M.W., Løkkeborg, S., 2009. Reflex impairment as a measure of vitality and survival potential of Atlantic cod (Gadus morhua). Fisheries Bull. 107, 395-402.

Kelleher K., 2005. Discards in the world"s marine fisheries. An update, FAO fisheries technical paper. no. 470. FAO, Rome

Macbeth, W.G., Broadhurst, M.K., Paterson, B.D., Wooden, M.E.L., 2006. Reducing the short-term mortality of juvenile school prawns (Metapenaeus macleayi) discarded during trawling. ICES J. Marine Science. 63, 831-839.

Macher, C., Guyader, O., Talidec, C., Bertignac, M., 2008. A cost-benefit analysis of improving trawl selectivity in the case of discards: The Nephrops norvegicus fishery in the Bay of Biscay. Fisheries Res. 92, 76-89. 
Morizur, Y., Charueau, A., Rivoalen, J.J., 1982. Survie des rejets de Nephrops norvegicus dans le Golfe de Gascogne et en mer Celtique. ICES CM 1982 / B:13 (Note N).

Neilson, J.D., Waiwood, K.G. and Smith, S.J., 1989. Survival of Atlantic Halibut (Hippoglossus hippoglossus) caught by longline and otter trawl gear. Canadian Journal of Fisheries and Aquatic Sciences. 46, 887-897

Revill A, Dunlin G, Holst R, 2006. Selective properties of the cutaway trawl and several other commercial trawls used in the Farne Deeps North Sea Nephrops fishery. Fisheries Res. 81, 268-275.

Revill A, 2012. Survival of discarded fish. A rapid review of studies on discard survival rates. DG MARE A2. Request for services Commitment No.S12.615631.

Revill, A.S., Broadhurst, M.K., Millar, R.B., 2013. Mortality of adult plaice, Pleuronectes platessa and sole, Solea solea discarded from English Channel beam trawlers. Fisheries Res. 147, 320-326.

Ridgway, I.D., Taylor, A.C., Atkinson, R.J.A, Chang, E.S., Neil, D.M., 2006. Impact of capture method and trawl duration on the health status of the Norway lobster, Nephrops norvegicus. Journal of Experimental Marine Biology and Ecology. 339, 135-147.

STECF,2013. Expert working group on a Landing Obligation in EU Fisheries (EWG 13-16). Retrieved from http://stecf.jrc.ec.europa.eu/reports/discards, 01/09/2015.

Tenningen, M., Vold, A., Olsen, R.E., 2012. The response of herring to high crowding densities in purse-seines: survival and stress reaction. ICES J. Marine Science. 69(8), 1523-1531.

Valentinsson, D., Ulmestrand, M., 2008. Species-selective Nephrops trawling: Swedish grid experiments. Fisheries Res. 90, 109-117.

Wileman, D.A., Sangster, G.I., Breen, M., Ulmestrand M., Soldal, A.V., Harris, R.R., 1999. Roundfish and Nephrops survival after escape from commercial fishing gear. Final Report - EC Contract No: FAIR-CT95-0753.

Yergey, M.E., Grothues, T.M., Able, K.W., Crawford, C., DeCristofer, K., 2012. Evaluating discard mortality of summer flounder (Paralichthys dentatus) in the commercial trawl fishery: Developing acoustic telemetry techniques. Fisheries Res. 115-116, 72-81. 